\title{
Plantar pressures and relative metatarsal lengths in older people with and without forefoot pain
}

\author{
Hylton B Menz ${ }^{1 *}$, Mohammad R Fotoohabadi ${ }^{1}$, Shannon E Munteanu ${ }^{1,2}$, Gerard V Zammit ${ }^{1,2}$, Mark F Gilheany ${ }^{1}$
}

From 3rd Congress of the International Foot and Ankle Biomechanics Community

Sydney, Australia. 11-13 April 2012

\section{Background}

It has been suggested that plantar forefoot pain ('metatarsalgia') may be caused by the presence of abnormally long lesser metatarsals leading to excessive loading of the metatarsal heads when walking. However, evidence to support this proposed mechanism is limited. Therefore, the objective of this study was to determine whether plantar pressures during gait and the relative lengths of the lesser metatarsals differ between older people with and without plantar forefoot pain.

\section{Materials and methods}

Dynamic plantar pressure assessment during walking was undertaken using the Tekscan MatScan ${ }^{\circledR}$ system in 118 community-dwelling older people (44 males and 74 females, mean age 74.0 years, standard deviation [SD] 5.9), 43 (36\%) of whom reported current or previous plantar forefoot pain. Seven individual "masks" were constructed to determine peak pressures under the hallux, the lesser toes, metatarsal head 1, metatarsal head 2, metatarsal heads 3 to 5 , the midfoot and the heel (see Figure 1). The relative lengths of metatarsals 1 to 5 were

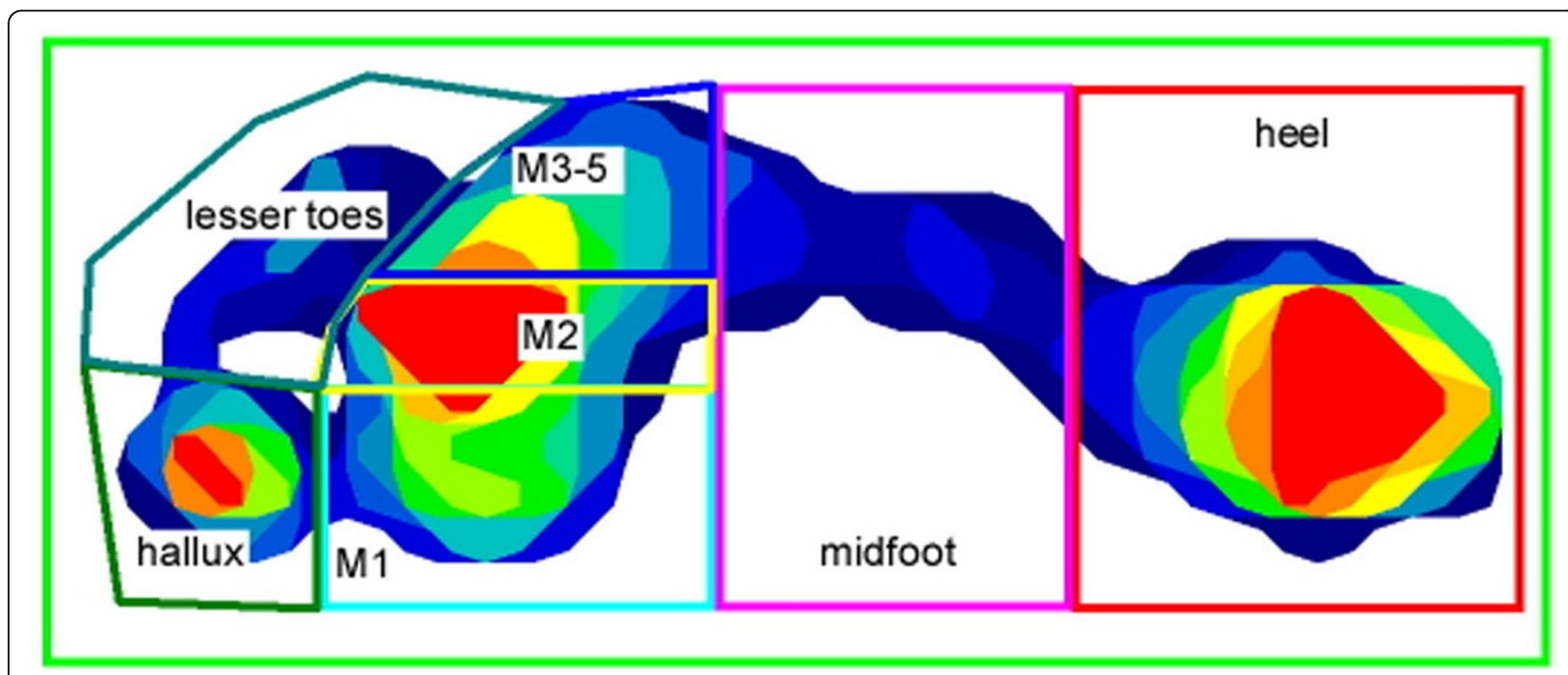

Figure 1 Mask template used for plantar pressure analysis.

\footnotetext{
* Correspondence: h.menz@latrobe.edu.au

${ }^{1}$ Musculoskeletal Research Centre, La Trobe University, Bundoora, Victoria 3086, Australia

Full list of author information is available at the end of the article
}

(c) 2012 Menz et al; licensee BioMed Central Ltd. This is an Open Access article distributed under the terms of the Creative Commons 
determined from weightbearing dorsoplantar $\mathrm{x}$-rays using the Maestro [1] and Coughlin [2] techniques.

\section{Results}

There were no differences between the groups for age, bodyweight or walking speed. Participants with current or previous plantar forefoot pain exhibited significantly greater peak plantar pressure under metatarsal heads 3 to $5\left(1.93\right.$ [SD 0.41] versus $1.74[0.48] \mathrm{kg} / \mathrm{cm}^{2}, \mathrm{p}=0.032$; Cohen's $d=0.42$ - medium effect). However, there were no differences in relative metatarsal lengths between the groups.

\section{Conclusions}

Older people with current or previous forefoot pain display greater peak plantar pressures under the lateral metatarsal heads when walking, but do not exhibit relatively longer lesser metatarsals. Other factors may be responsible for the observed pressure increase, such as reduced range of motion of the metatarsophalangeal joints and increased stiffness of plantar soft tissues.

\section{Author details}

${ }^{1}$ Musculoskeletal Research Centre, La Trobe University, Bundoora, Victoria 3086, Australia. ${ }^{2}$ Department of Podiatry, La Trobe University, Bundoora,

Victoria 3086, Australia.

Published: 10 April 2012

\section{References}

1. Maestro M, Besse $J$, Ragusa M, Bertonnaud E: Forefoot morphotype study and planning method for forefoot osteotomy. Foot Ankle Clin 2003,

8:695-710.

2. Coughlin MJ: Crossover second toe deformity. Foot Ankle 1987, 8:29-39.

\section{doi:10.1186/1757-1146-5-S1-P16}

Cite this article as: Menz et al:: Plantar pressures and relative metatarsal lengths in older people with and without forefoot pain. Journal of Foot and Ankle Research 2012 5(Suppl 1):P16.

\section{Submit your next manuscript to BioMed Central} and take full advantage of:

- Convenient online submission

- Thorough peer review

- No space constraints or color figure charges

- Immediate publication on acceptance

- Inclusion in PubMed, CAS, Scopus and Google Scholar

- Research which is freely available for redistribution

Submit your manuscript at www.biomedcentral.com/submit 